\title{
Application of metabolomics part II: Focus on fatty acids and their metabolites in healthy adults
}

\author{
DIMITRIOS TSOUKALAS ${ }^{1-3^{*}}$, ATHANASIOS K. ALEGAKIS ${ }^{1,4^{*}}$, PERSEFONI FRAGKIADAKI $^{1,4^{*}}$, \\ EVANGELOS PAPAKONSTANTINOU ${ }^{2}$, GERASIMOS TSILIMIDOS $^{2}$, FRANCO GERACI ${ }^{3}$, EVANGELIA SARANDI ${ }^{1,2}$, \\ DRAGANA NIKITOVIC ${ }^{5}$, DEMETRIOS A. SPANDIDOS ${ }^{6}$ and ARISTIDES TSATSAKIS ${ }^{1,3,4}$ \\ ${ }^{1}$ Laboratory of Toxicology and Forensic Sciences, Medical School, University of Crete, 71003 Heraklion; \\ ${ }^{2}$ Metabolomic Medicine Clinic, 10674 Athens, Greece; ${ }^{3}$ European Institute of Nutritional Medicine, E.I.Nu.M, \\ 00198 Rome, Italy; ${ }^{4}$ Toxplus Spin-Off S.A., 71601 Heraklion; ${ }^{5}$ Laboratory of Anatomy-Histology-Embryology, and \\ ${ }^{6}$ Laboratory of Clinical Virology, School of Medicine, University of Crete, 71003 Heraklion, Greece
}

Received September 13, 2018; Accepted November 2, 2018

DOI: $10.3892 /$ ijmm.2018.3989

\begin{abstract}
Fatty acids (FAs) play critical roles in health and disease. The detection of FA imbalances through metabolomics can provide an overview of an individual's health status, particularly as regards chronic inflammatory disorders. In this study, we aimed to establish sensitive reference value ranges for targeted plasma FAs in a well-defined population of healthy adults. Plasma samples were collected from 159 participants admitted as outpatients. A total of 24 FAs were analyzed using gas chromatography-mass spectrometry, and physiological values and $95 \%$ reference intervals were calculated using an approximate method of analysis. The differences among the age groups for the relative levels of stearic acid $(\mathrm{P}=0.005)$, the omega-6/omega-3 ratio $(\mathrm{P}=0.027)$, the arachidonic acid/eicosapentaenoic acid ratio $(\mathrm{P}<0.001)$ and the linoleic acid-produced dihomo-gamma-linolenic acid $(\mathrm{P}=0.046)$ were statistically significant. The majority of relative FA levels were higher in males than in females. The levels of myristic acid $(\mathrm{P}=0.0170)$ and docosahexaenoic acid $(\mathrm{P}=0.033)$ were significantly different between the sexes. The reference values for
\end{abstract}

Correspondence to: Professor Aristides Tsatsakis, Laboratory of Toxicology and Forensic Sciences, Medical School, University of Crete, P.O. Box 1393, 71003 Heraklion, Greece

E-mail: toxlab.uoc@gmail.com

*Contributed equally

Abbreviations: FA, fatty acid; MUFA, monounsaturated fatty acid; PUFA, polyunsaturated fatty acid; LA, linoleic acid; ALA, alphalinolenic acid; AA, arachidonic acid; EPA, eicosapentaenoic acid; DHA, docosahexaenoic acid; COX, cyclooxygenase; LOX, lipoxygenase; CYP, cytochrome P450; RV, reference value; OA, organic acid; GC-MS, gas chromatography-mass spectrometry; SFA, saturated fatty acid; DGLA, LA-produced dihomo-gamma-linolenic acid; FXR, Farnesoid $\mathrm{X}$ receptor; FFAs, free fatty acids

Key words: fatty acids, adults, metabolomic, reference values, metabolism the FAs examined in this study represent a baseline for further studies examining the reproducibility of this methodology and sensitivities for nutrient deficiency detection and investigating the biochemical background of pathological conditions. The application of these values to clinical practice will allow for the discrimination between health and disease and contribute to early prevention and treatment.

\section{Introduction}

Fatty acids (FAs) are major constituents of lipids and play essential roles in the diverse biological functions of the human body. They are key components of the cell membrane, provide an essential source of cellular fuel and energy storage and are involved in critical signal transduction pathways. Depending on the chemical structure, an FA can be a saturated FA (SFA), a monounsaturated FA (MUFA), or a polyunsaturated FA (PUFA). Apart from the essential PUFAs [i.e., linoleic acid (LA) and alpha-linolenic acid (ALA)], the human body can synthesize the majority of FAs. LA and ALA are precursors for omega-3 and omega-6 FAs, respectively, and can only be obtained from the diet. LA is metabolized to arachidonic acid (AA) and is mainly found in meat and eggs from grain-fed animals, vegetable oils, nuts and seeds (1). ALA and its derivatives, eicosapentaenoic acid (EPA) and docosahexaenoic acid (DHA), are found in fish oil, flaxseeds, walnuts, and seeds (2). Eicosanoids are metabolites produced from AA, EPA and DHA under the activity of cyclooxygenases (COXs), lipoxygenases (LOXs) and cytochrome P450s (CYPs). Eicosanoids play critical roles in the inflammation process (Fig. 1). The Western diet now provides a 15:1 ratio of omega-6/omega-3 ratio that is markedly higher compared with such levels a century ago (3). The consumption of a Westernized diet is associated with a higher risk of the onset of chronic disease (4,5). An unbalanced omega-6 to omega-3 ratio results in an increased production of AA and pro-inflammatory eicosanoids (6). Due to the enzyme competition, the production of anti-inflammatory EPA/DHA-derived eicosanoids is reduced. Overall, therefore, this imbalance promotes a pro-inflammatory profile (7). It is already known that type- 2 diabetes and its complications are associated with 
lipid metabolism disorder and Farnesoid X receptor (FXR) plays an important role in regulating lipid and glucose metabolism. Liu et al demonstrated that the activation of FXR in mice induced the activation of the AMPK-ACC-CPT1 pathway, a signaling pathway promoting fatty acid oxidation and achieving its lipid-lowering effect (8). Additionally, it has been established that in individuals with high-fat diet-induced type 2 diabetes, monounsaturated free fatty acids (FFAs) can serve as a predictive indicator of vascular restenosis following interventional therapy (9). Chronic diseases often occur when inflammation is persistent or has not been effectively resolved (10).

Disorders such as cardiovascular disease, diabetes, several forms of cancer and autoimmune diseases have the hallmarks of chronic non-resolving inflammation, and the altered metabolic pathways play crucial roles that contribute to the pathogenesis of inflammation (11-14). Genomic studies have contributed to the identification of genes that can affect the risk of these diseases. For example, genetic variations of paraoxonase genes have been shown to be associated with cardiovascular disease and the differential FA composition in human adipose tissue (15). However, the clinical application of these findings is limited due to the fact that genetic alterations do not always manifest as phenotypic variations $(16,17)$. A more targeted approach includes the study of metabolism, particularly the use of tools developed for the study of FA metabolism (18).

The evaluation of the FA status as part of metabolomics profiling can provide invaluable input for the identification of metabolic disruption prior to the onset of symptoms, and can predict disease risk (19-21). Metabolites are products of gene expression regulated by epigenetic factors (e.g., nutrition, stress and exercise). Metabolites reflect the current state of health and provide evidence of previous conditions (22-24). The simultaneous profiling of distinct biological pathways that includes many metabolites can provide an overview of the metabolic status. This approach can be used for the accurate identification of specific biomarkers that correspond to different clinical conditions (25).

The clinical evaluation of the FA levels associated with acquired metabolic diseases requires the generation of sensitive reference values (RVs). RVs limited to a narrow range are necessary for the reliable detection of small differences in FA levels in a population. Population studies have been used to examine baseline FA levels in different populations (26-28). However, variabilities in the evaluation methods used, population characteristics and units used to express the results of FAs (29) hinders the establishment of reference ranges that could be used as complementary diagnostic tools. To the best of our knowledge, the concentration of total FAs (TFAs) in the Greek population has not yet been defined. The findings of a previous study included only selected unsaturated FAs (30). The quantification of many FAs and the assessment of their relative levels can provide a more comprehensive description of FA metabolism than the study of a few selected FAs (19).

A reliable and valid method with which to evaluate the FA composition that can be used in large clinical studies as markers of deficiency or excess is needed (31). Previous clinical studies on the roles of FAs in health and disease have revealed differences in factors, including demographics, the background diet of the study population, the use of supplements, differences in FA analysis methods, variability in clinical parameters and disease background $(32,33)$. Additionally, the levels of FAs must be comparable to a set of RVs that reflect the sociodemographic characteristics of the general population, adjusted for location and dietary habits (34).

As part of a targeted FA profiling approach, we used a highly sensitive method to detect very low quantities of FA molecules. The high resolving power of gas chromatography (GC) and the extended possibility for identification of metabolites inherent in mass spectroscopy (MS) methods can be applied in large-scale studies; the use of these methods results in a short turnaround time for the analysis of samples (35-37). In a previous population study, we used this approach to analyze organic acids (OAs) in healthy Greek individuals and found that we could detect small differences among metabolites (38).

The aim of this study was to evaluate 24 total plasma FAs (i.e., omega-3 and omega-6 PUFAs, MUFAs and SFAs) to obtain a comprehensive quantitative and qualitative assessment of FA values.

\section{Materials and methods}

Subjects. The 159 participants enrolled in this study were outpatients admitted to a private clinic in Athens in the period of January, 2013 to July, 2015. From each of the participants a blood sample was collected and their medical records were obtained. Patients were eligible for the study if they were healthy, not suffering from any chronic disease, non-obese and fasted. The results of the medical examinations indicated that all study participants were healthy. No chronic diseases were diagnosed in the population, and none of the participants used medication or supplements at the time of the clinic visit. Patients that did not meet the inclusion criteria (e.g., disease, obesity or non-fasting) were not included in this study. All procedures performed in studies involving human participants were under the ethical standards with the 1964 Helsinki declaration and its later amendments, or comparable ethical standards. An informed consent was obtained from all participants for this study according to the EU General Data Protection Regulation (GDPR).

Chemicals. Methyl nonadecanoate (74208, Honeywell Fluka ${ }^{\mathrm{TM}}$; Honeywell, Seelze, Germany) was used as an internal standard. A mixture of FA methyl esters (47885-U; Supelco-Sigma-Aldrich, St. Louis, MO, USA) was used for the calibration of the standard mixture. All other solvents used were of the highest purity available [methanol, n-hexane (both from Merck KGaA, Darmstadt, Germany), $\mathrm{HCl}$ (301721] and 2,6-i-tert-butyl-4-methylphenol (BHT, B1378l) (both from Sigma-Aldrich).

Sample preparation. The analysis of TFAs includes the hydrolysis of the ester bonds and the simultaneous formation of FA methyl esters that are separated using GC-MS. Blood samples were obtained from adults following a 12 -h fast. The samples were centrifuged at $1,500 \mathrm{xg}$ at $4^{\circ} \mathrm{C}$, and the plasma specimens were stored at $-20^{\circ} \mathrm{C}$ until analysis, but no longer than $24 \mathrm{~h}$ to avoid degradation. If hemolysis occurred during collection, the sample was discarded, and blood collection was repeated. Following the addition of the standard internal mixture (200 $\mu 1$ methyl nonadecanoate in hexane containing 


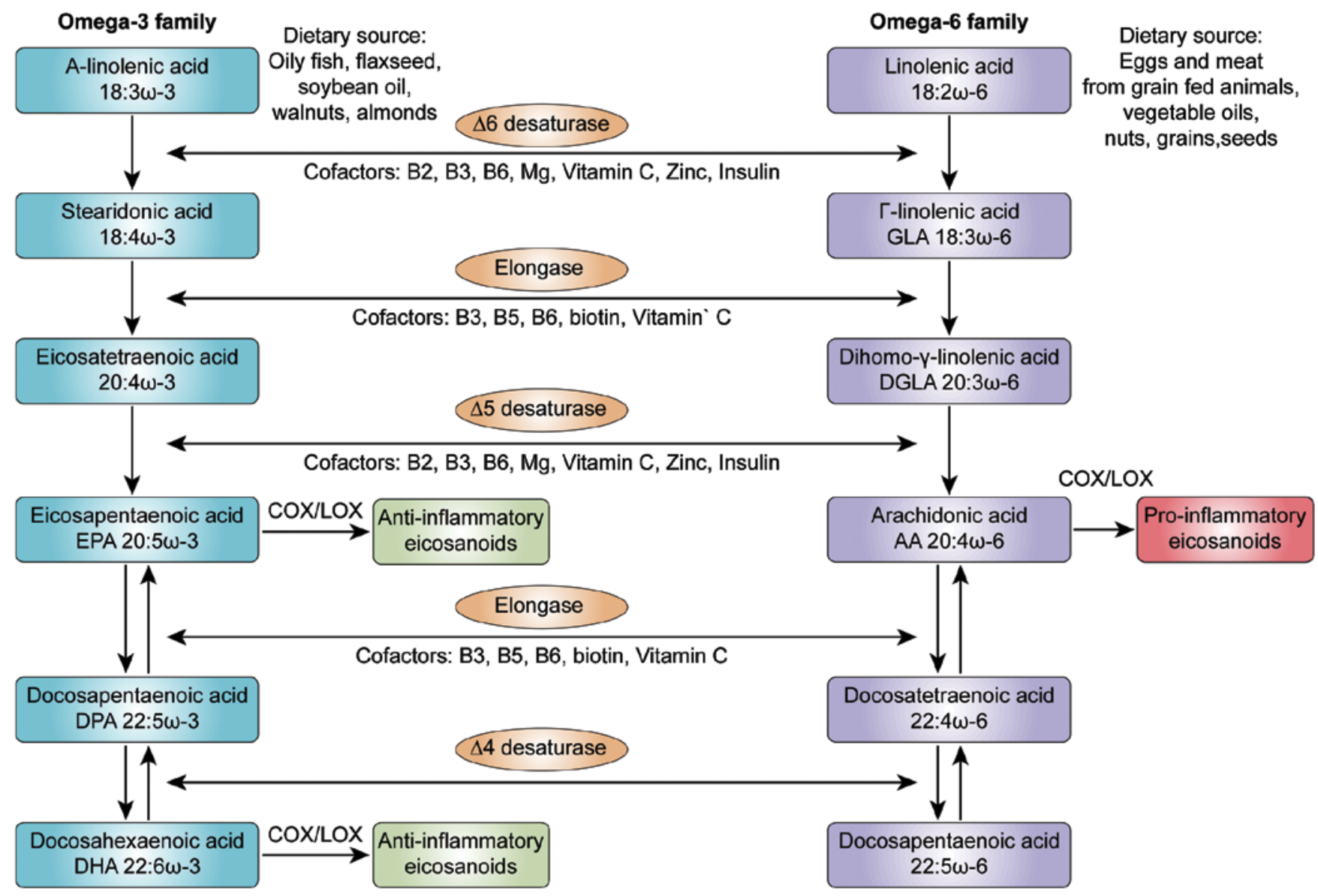

Figure 1. Eicosanoid synthesis pathway. Lipid mediators are generated from omega-3 and omega-6 polyunsaturated fatty acids (PUFAs) in the lipoxygenase (LOX) and cyclooxygenase (COX) pathways. Conversion of precursor omega-3 and omega-6 PUFAs to their derivatives is facilitated by desaturase and elongase in the presence of cofactors. Pro-inflammatory 4-series leukotrienes, 2-series prostaglandins, and thromboxane A2 are derived from AA, and eicosapentaenoic acid (EPA) derived 3-series prostaglandins, and 5-series leukotrienes have reduced inflammatory properties. Pro-resolving lipoxins derive from AA; resolvins, protectins, and maresins are generated from DHA and EPA.

BHT) to $100 \mu \mathrm{l}$ plasma, the FAs were hydrolyzed and derivatized into methyl esters by the addition of $5 \% \mathrm{v} / \mathrm{v}$ methanolic $\mathrm{HCl}$. Transmethylation was performed at $90^{\circ} \mathrm{C}$ for $60 \mathrm{~min}$. The samples were then brought to room temperature, and the FA methyl esters were extracted using hexane and transferred to GC injection vials with a crimp cap. As previously described, sample preparation did not include lipid extraction prior to methylation as MS allows the direct detection and identification of FAs in plasma without affecting quantity or quality (39).

$G C-M S$. The sample injection volume was $1 \mu 1$, and helium was used as a carrier gas. The analysis was performed on an Agilent 6890/5975C GC-MS operating in electron ionization mode (Agilent Technologies, Santa Clara, CA, USA). The separation of FA methyl esters was accomplished using an HP-5 ms capillary column (30 m x $250 \mu \mathrm{m} \times 0.25 \mu \mathrm{m})$. The initial oven temperature was $70^{\circ} \mathrm{C}$, the ramp rate was $4^{\circ} \mathrm{C} / \mathrm{min}$, and the final temperature was $290^{\circ} \mathrm{C}$, held for $4 \mathrm{~min}$. The acquisition was in the scan mode.

Statistical analysis. The results of the descriptive statistics analysis for the 24 FAs are presented as measures of tendency, including values for minimum, maximum, median, quartiles (1st and 3rd), and 90th percentile and dispersion (95\% confidence intervals) were estimated. The sums of the saturated, unsaturated (e.g., MUFA and PUFA), omega-3 and omega-6 FAs were calculated. The FA RVs were set using the approximate $95 \%$ confidence intervals for the mean values (mean $\pm 1.96 \times$ standard deviation). In cases where negative values were estimated, the lower levels were presented as below zero $(<0)$. Between-group differences in the FA level were tested using the non-parametric Mann-Whitney test for 2 groups and the Kruskal-Wallis test for $>2$ groups. A Dunn's t-test followed the Kruskal-Wallis test for post hoc bivariate comparisons. IBM SPSS Statistics V22.0 software (IBM SPSS, Armonk, NY, USA) was used for the analysis of the data. Levels of $\mathrm{a}=0.05$ was set as cut-off values for the level of significance.

\section{Results}

The evaluation of the FA levels was performed using plasma samples of 159 healthy adults (males, $44.7 \%, \mathrm{n}=71$; females, $55.3 \%, \mathrm{n}=88)$. The mean age ( \pm standard deviation) of the participants was $39.7( \pm 9.1)$ years. The age distribution did not differ significantly between the sexes $(\mathrm{P}=0.307)$ (data not shown). The mean values of BMI and waist circumference were 25.5 and $73 \mathrm{~cm}$, respectively. The samples were divided into 4 groups according to age for the statistical analysis [i.e., adults $\leq 30$ years $(16.4 \%), 31-40$ years $(34.6 \%), 41-50$ years $(37.7 \%)$ and $>50$ years $(11.3 \%)]$. 
Table I. Descriptive statistics for plasma fatty acid concentrations $(\mu \mathrm{mol} / \mathrm{l})$.

\begin{tabular}{|c|c|c|c|c|c|c|c|}
\hline Fatty acids & Min & 25 & Median & 75 & 90 & Max & 95\% LL-95\% UL \\
\hline Total saturated & 728.7 & 1895.3 & 2169.0 & 2525.2 & 3022.6 & 4192.3 & 1149.1-3349.5 \\
\hline $\mathrm{C} 12: 0$ & 0.3 & 6.4 & 13.2 & 22.8 & 41.4 & 66.7 & $<0-46.7$ \\
\hline C14:0 & 16.7 & 35.7 & 51.0 & 71.1 & 87.5 & 183.6 & $<0-115.8$ \\
\hline $\mathrm{C} 15: 0$ & 3.4 & 10.0 & 12.3 & 15.3 & 20.3 & 39.8 & $3.5-23.0$ \\
\hline C16:0 & 781.3 & 1306.7 & 1478.0 & 1725.2 & 2080.4 & 2704.1 & $806.1-2291.5$ \\
\hline $\mathrm{C} 17: 0$ & 8.5 & 13.6 & 16.8 & 19.6 & 23.7 & 45.5 & 7.7-26.9 \\
\hline C18:0 & 8.5 & 528.8 & 625.1 & 702.5 & 771.0 & 1054.7 & $357.0-885.8$ \\
\hline C20:0 & 3.5 & 11.8 & 14.3 & 17.3 & 19.9 & 56.8 & 4.1-25.7 \\
\hline $\mathrm{C} 22: 0$ & 7.5 & 29.7 & 35.9 & 44.7 & 50.6 & 76.2 & $14.6-59.4$ \\
\hline $\mathrm{C} 24: 0$ & 14.1 & 26.1 & 30.6 & 38.4 & 43.2 & 66.6 & $15.3-49.2$ \\
\hline MUFAs & 389.0 & 739.5 & 980.3 & 1302.5 & 1703.9 & 2576.1 & $228.5-1942.4$ \\
\hline $\mathrm{C} 14: 1$ & 0.0 & 1.0 & 1.0 & 1.0 & 2.7 & 13.2 & $<0-4.6$ \\
\hline C15:1 & 0.1 & 1.0 & 1.0 & 1.0 & 13.3 & 40.1 & $<0-15.7$ \\
\hline C16:1n-7 & 7.8 & 30.9 & 46.7 & 72.2 & 100.0 & 864.3 & $<0-206.4$ \\
\hline C18:1n-9cis & 310.7 & 639.2 & 864.5 & 1147.0 & 1471.7 & 2365.1 & $169.6-1734.2$ \\
\hline C20:1n-9 & 0.1 & 1.0 & 2.0 & 4.0 & 7.6 & 20.4 & $<0-9.1$ \\
\hline C22:1n-9 & 0.1 & 1.0 & 1.0 & 1.0 & 1.5 & 26.3 & $<0-5.9$ \\
\hline C24:1n-9 & 8.0 & 59.0 & 69.0 & 83.0 & 91.8 & 149.0 & $33.1-108.8$ \\
\hline PUFAs & 968.0 & 1746.1 & 2123.7 & 2574.9 & 3134.3 & 4262.5 & $947.6-3528.0$ \\
\hline C18:2n-6 & 588.6 & 1141.7 & 1420.5 & 1804.2 & 2216.4 & 3317.3 & $520.8-2494.8$ \\
\hline C18:3n-3 & 0.8 & 2.5 & 7.7 & 18.1 & 29.4 & 53.4 & $<0-36.2$ \\
\hline$C 18: 3 n-6$ & 0.6 & 3.1 & 9.2 & 21.1 & 32.2 & 58.8 & $<0-40.3$ \\
\hline$C 20: 3 n-6$ & 24.6 & 73.5 & 96.8 & 124.0 & 160.9 & 269.4 & $17.3-187.8$ \\
\hline C20:4n-6 & 188.2 & 296.3 & 349.7 & 443.0 & 517.7 & 732.5 & $160.8-587.3$ \\
\hline$C 22: 6 n-3$ & 18.9 & 79.0 & 113.2 & 156.1 & 183.7 & 437.7 & $<0-251.2$ \\
\hline$C 20: 5 n-3$ & 9.3 & 27.9 & 34.3 & 54.4 & 91.4 & 245.3 & $<0-123.8$ \\
\hline$C 20: 3 n-3$ & 1.0 & 42.5 & 61.1 & 79.6 & 101.7 & 180.0 & $<0-127.8$ \\
\hline Ratio AA:EPA & 1.8 & 6.8 & 10.1 & 14.1 & 17.6 & 26.7 & $0.0-21.5$ \\
\hline Total $\omega 6$ & 880.4 & 1580.1 & 1896.2 & 2307.7 & 2801.7 & 3894.3 & $833.1-3161.1$ \\
\hline Total $\omega 3$ & 47.4 & 176.8 & 217.3 & 281.3 & 366.3 & 774.6 & $20.9-464.5$ \\
\hline$\omega 6: \omega 3$ & 3.3 & 7.2 & 8.6 & 10.7 & 13.4 & 36.2 & $1.4-17.3$ \\
\hline Total FA & 3097.0 & 4526.1 & 5240.1 & 6244.2 & 8123.7 & 10322.8 & $2639.8-8504.2$ \\
\hline
\end{tabular}

Percentiles, tendency values and approximate 95\% confidence intervals (95\% lower limit (LL) and 95\% upper limit (UL) for individual fatty acids and total saturated fatty acids, MUFAs and PUFAs. MUFA, monounsaturated fatty acid; PUFA, polyunsaturated fatty acid; AA, arachidonic acid (20:4n-6); EPA, eicosapentaenoic acid (20:5n-3).

The mean, max, quartiles, 90th percentile and 95\% confidence interval of the mean are presented in Table I. Based on these measures, the physiological levels of an individual should be included between 1149.1-3349.5 $\mu \mathrm{mol} / 1$ for TFAs, 228.5-1942.4 $\mu \mathrm{mol} / 1$ for MUFAs and 947.6-3528.0 $\mu \mathrm{mol} / 1$ for PUFAs. A more detailed list of percentiles and quartiles is presented in Table S1.

Table II presents the results of the differences in FA composition among the distinct age groups, expressed as TFA percentage (\% TFAs). There was a decreasing trend in the mean relative levels of saturated pentadecanoic acid (C15:0; $\mathrm{P}=0.031)$ and stearic acid $(\mathrm{C} 18: 0 ; \mathrm{P}=0.005)$ in the adults from the different age groups. The highest values were found in adults $<30$ years of age. Conversely, the relative levels of cis-10 pentadecanoic acid $(\mathrm{C} 15: 1 ; \mathrm{P}=0.011)$ increased considerably with age. In other two monosaturated fatty acids there was a statistically significant difference $(\mathrm{P}<0.05)$ when median values instead of means were compared. These acids were: Myristoleic acid (C14:1; $\mathrm{P}=0.050)$ and dihomo-gamma-linolenic acid $(\mathrm{C} 20: 3 \mathrm{n} 6 ; \mathrm{P}=0.046)$. The decreasing fact with age, was not observable when mean values were presented.

Between ratios the omega-6/omega-3ratios, examined as medians, revealed a significant difference between age groups $(\mathrm{P}=0.027)$. The decreasing age trend was not clear when mean ratios were presented. with a decreasing trend with the strongest statistically significant finding found for the comparison 
Table II. Age group differences in measured FAs as \% total FA composition.

\begin{tabular}{|c|c|c|c|c|c|}
\hline \multirow[b]{2}{*}{ Fatty acids } & \multicolumn{4}{|c|}{ Age groups ${ }^{\mathrm{a}}$} & \multirow[b]{2}{*}{ P-value } \\
\hline & $\begin{array}{l}\leq 30 \text { years } \\
\quad(n=26)\end{array}$ & $\begin{array}{c}31-40 \text { years } \\
\quad(n=55)\end{array}$ & $\begin{array}{c}41-50 \text { years } \\
\quad(n=60)\end{array}$ & $\begin{array}{l}\geq 51 \text { years } \\
\quad(n=18)\end{array}$ & \\
\hline Total saturated & $41.3(4.4)$ & $41.5(5.0)$ & $40.1(5.6)$ & $40.9(7.4)$ & 0.566 \\
\hline $\mathrm{C} 12: 0$ & $0.3(0.3)$ & $0.3(0.3)$ & $0.3(0.3)$ & $0.3(0.3)$ & 0.722 \\
\hline C14:0 & $1(0.4)$ & $1(0.4)$ & $1.1(0.4)$ & $0.9(0.2)$ & 0.193 \\
\hline C15:0 & $0.3(0.1)$ & $0.2(0.1)$ & $0.2(0.1)$ & $0.2(0.1)$ & 0.031 \\
\hline C16:0 & $28.5(3.0)$ & $28.4(3.5)$ & $27.4(5.5)$ & $27.4(5.1)$ & 0.189 \\
\hline C17:0 & $0.3(0.1)$ & $0.3(0.1)$ & $0.3(0.1)$ & $0.3(0.1)$ & 0.090 \\
\hline C18:0 & $13.5(3.1)$ & $12.6(4.2)$ & $10.8(3.6)$ & $11.2(4.2)$ & 0.005 \\
\hline C20:0 & $0.3(0.1)$ & $0.3(0.1)$ & $0.3(0.1)$ & $0.3(0.1)$ & 0.105 \\
\hline C22:0 & $0.6(0.3)$ & $0.7(0.2)$ & $0.7(0.1)$ & $0.7(0.2)$ & 0.719 \\
\hline $\mathrm{C} 24: 0$ & $0.6(0.2)$ & $0.6(0.2)$ & $0.6(0.1)$ & $0.6(0.1)$ & 0.825 \\
\hline MUFAs & $17.9(4.1)$ & $18.9(4.1)$ & $19.6(3.8)$ & $19.3(3.9)$ & 0.144 \\
\hline C14:1 & $0.03(0.02)$ & $0.03(0.02)$ & $0.02(0.02)$ & $0.02(0.01)$ & 0.050 \\
\hline C15:1 & $0(0.1)$ & $0.1(0.1)$ & $0.1(0.2)$ & $0.1(0.1)$ & 0.011 \\
\hline C16:1n-7 & $1(0.5)$ & $1.3(2.3)$ & $1.1(0.6)$ & $0.8(0.3)$ & 0.156 \\
\hline C18:1n-9cis & $15.6(3.9)$ & $16.4(3.9)$ & $17.3(3.7)$ & $17.1(3.9)$ & 0.161 \\
\hline C20:1n-9 & $0.1(0)$ & $0.1(0)$ & $0.1(0.1)$ & $0.1(0.1)$ & 0.219 \\
\hline C22:1n-9 & $0.05(0.04)$ & $0.06(0.4)$ & $0.05(0.05)$ & $0.07(0.06)$ & 0.009 \\
\hline $\mathrm{C} 24: 1 \mathrm{n}-9$ & $1.3(0.4)$ & $1.2(0.4)$ & $1.2(0.4)$ & $1.3(0.3)$ & 0.545 \\
\hline PUFAs & $40.9(3.5)$ & $39.6(4.4)$ & $40.3(4.5)$ & $39.8(4.6)$ & 0.807 \\
\hline C18:2n6 & $27.5(3.8)$ & $26.4(5)$ & $27.2(4.5)$ & $26.9(5.3)$ & 0.835 \\
\hline C18:3n3 & $0.2(0.1)$ & $0.2(0.2)$ & $0.2(0.2)$ & $0.2(0.2)$ & 0.913 \\
\hline C18:3n6 & $0.2(0.1)$ & $0.2(0.2)$ & $0.2(0.2)$ & $0.2(0.2)$ & 0.745 \\
\hline C20:3n6 & $177(0.7)$ & $2(0.7)$ & $1.8(0.6)$ & $1.6(0.5)$ & 0.046 \\
\hline C20:4n6 & $7.1(0.9)$ & $7.1(1.4)$ & $6.6(1.8)$ & $6.4(1.1)$ & 0.053 \\
\hline $\mathrm{C} 22: 6 \mathrm{n} 3$ & $2.2(1)$ & $2(0.8)$ & $2.3(1.1)$ & $2.6(0.7)$ & 0.051 \\
\hline $\mathrm{C} 20: 5 \mathrm{n} 3$ & $0.9(0.7)$ & $0.6(0.3)$ & $1(0.7)$ & $1(0.6)$ & 0.006 \\
\hline $\mathrm{C} 20: 3 \mathrm{n} 3$ & $1.1(0.5)$ & $1.2(0.5)$ & $1(0.5)$ & $1(0.5)$ & 0.057 \\
\hline Ratio AA:EPA & $0.2(0.1)$ & $0.3(0.1)$ & $0.2(0.1)$ & $0.2(0.1)$ & $<0.001$ \\
\hline Total $\omega 6$ & 36.5 (3.7) & $35.6(4.8)$ & $35.9(4.3)$ & $35.1(4.9)$ & 0.914 \\
\hline Total $\omega 3$ & $4.4(1.4)$ & $4.1(1.2)$ & $4.4(1.7)$ & $4.8(1.2)$ & 0.244 \\
\hline Ratio $\omega 6: \omega 3$ & $0.2(0.1)$ & $0.2(0.1)$ & $0.2(0.1)$ & $0.2(0.1)$ & 0.027 \\
\hline
\end{tabular}

FA, fatty acid; MUFA, monounsaturated fatty acid; PUFA, polyunsaturated fatty acid; AA, arachidonic acid (20:4n-6); EPA, eicosapentaenoic acid (20:5n-3). ${ }^{2}$ Data for the FA measurements in the age groups are presented as the means (SD).

between the AA/EPA ratio and age $(\mathrm{P}<0.001)$; there was a trend in an increasing value in the ratio until 40 years of age, and then a decline in the older participants. The total relative levels of the SFAs, MUFAs and PUFAs expressed as the $\%$ ratio of the TFAs were not markedly altered with age in males or females (Fig. 2). Statistically significant differences between the FA composition and sex were found for myristic acid (C14:0; $\mathrm{P}=0.017$ and DPA (C22:6n3; P=0.033) (Table III).

A comparative analysis of the relative FA levels (\% TFAs) was performed for our population dataset and a group of Canadian adults $(n=826)(27)$. The interquartile ranges (1st and 3rd quartile) were estimated, and similar levels were found for myristic acid (C14:0), pentadecanoic acid (C15:0), palmitic acid (C16:0) and stearic acid (C18:0) (Fig. 3). Further analysis of the mean relative FA levels compared with the results from 374 healthy Greek individuals from the ATTICA health and nutrition survey revealed similar levels in the majority of the FA groups (30) (Table S2).

\section{Discussion}

In the present study, metabolomic profiling of 24 FAs, including omega-3 and omega-6 PUFAs, MUFAs and SFAs was performed on a Greek population of 159 healthy adults to estimate sensitive RV ranges Metabolomic analysis has extensive application in the identification of variations in 
Table III. Sex group differences in measured fatty acids as \% total fatty acid composition.

\begin{tabular}{|c|c|c|c|c|c|}
\hline \multirow[b]{3}{*}{ Fatty acids } & \multicolumn{4}{|c|}{ Sex } & \multirow[b]{3}{*}{ P-value } \\
\hline & \multicolumn{2}{|c|}{ Female $(n=88)$} & \multicolumn{2}{|c|}{ Male $(\mathrm{n}=71)$} & \\
\hline & Mean (SD) & Median & Mean (SD) & Median & \\
\hline Total saturated & $40.6(5.7)$ & 39.48 & $41.3(5.1)$ & 41.0 & 0.308 \\
\hline $\mathrm{C} 12: 0$ & $0.3(0.2)$ & 0.2 & $0.4(0.3)$ & 0.3 & 0.094 \\
\hline C14:0 & $1.0(0.4)$ & 0.9 & $1.1(0.4)$ & 1.0 & 0.017 \\
\hline C15:0 & $0.2(0.1)$ & 0.2 & $0.2(0.1)$ & 0.2 & 0.246 \\
\hline C16:0 & $27.7(5.2)$ & 27.0 & $28.2(3.4)$ & 27.8 & 0.281 \\
\hline C17:0 & $0.3(0.1)$ & 0.3 & $0.3(0.1)$ & 0.3 & 0.254 \\
\hline C18:0 & $11.4(3.9)$ & 10.3 & $12.5(3.8)$ & 12.8 & 0.077 \\
\hline C20:0 & $0.3(0.1)$ & 0.3 & $0.3(0.1)$ & 0.3 & 0.846 \\
\hline $\mathrm{C} 22: 0$ & $0.7(0.2)$ & 0.7 & $0.7(0.2)$ & 0.7 & 0.458 \\
\hline $\mathrm{C} 24: 0$ & $0.6(0.1)$ & 0.6 & $0.6(0.2)$ & 0.6 & 0.058 \\
\hline MUFAs & $18.8(3.8)$ & 18.6 & $19.4(4.2)$ & 19.0 & 0.528 \\
\hline C14:1 & $0(0.0)$ & 0.0 & $0(0.0)$ & 0.0 & 0.657 \\
\hline C15:1 & $0.1(0.1)$ & 0.0 & $0.1(0.2)$ & 0.0 & 0.402 \\
\hline C16:1n-7 & $1(0.4)$ & 0.9 & $1.2(2.1)$ & 0.8 & 0.568 \\
\hline C18:1n-9cis & $16.6(3.7)$ & 16.4 & $16.8(3.9)$ & 16.7 & 0.726 \\
\hline C20:1n-9 & $0.1(0.1)$ & 0.0 & $0.1(0.1)$ & 0.0 & 0.849 \\
\hline C22:1n-9 & $0(0.1)$ & 0.0 & $0(0.0)$ & 0.0 & 0.300 \\
\hline C24:1n-9 & $1.2(0.4)$ & 1.2 & $1.3(0.4)$ & 1.2 & 0.935 \\
\hline PUFAs & $40.6(4.4)$ & 41.3 & $39.4(4.3)$ & 39.7 & 0.057 \\
\hline C18:2n6 & $27.5(4.4)$ & 27.7 & $26.2(4.8)$ & 26.3 & 0.072 \\
\hline C18:3n3 & $0.2(0.2)$ & 0.1 & $0.2(0.2)$ & 0.2 & 0.337 \\
\hline C18:3n6 & $0.2(0.2)$ & 0.2 & $0.2(0.2)$ & 0.2 & 0.291 \\
\hline C20:3n6 & $1.8(0.6)$ & 1.8 & $1.9(0.6)$ & 1.9 & 0.188 \\
\hline C20:4n6 & $6.8(1.5)$ & 6.7 & $6.9(1.5)$ & 6.8 & 0.572 \\
\hline $\mathrm{C} 22: 6 \mathrm{n} 3$ & $2.3(0.9)$ & 2.3 & $2.1(1.0)$ & 1.9 & 0.033 \\
\hline C20:5n 3 & $0.9(0.6)$ & 0.7 & $0.8(0.6)$ & 0.6 & 0.469 \\
\hline C20:3n3 & $1(0.5)$ & 1.1 & $1.1(0.5)$ & 1.1 & 0.148 \\
\hline Ratio AA:EPA & $0.2(0.1)$ & 0.2 & $0.2(0.1)$ & 0.2 & 0.392 \\
\hline Total $\omega 6$ & $36.3(4.4)$ & 36.8 & $35.2(4.5)$ & 35.3 & 0.127 \\
\hline Total $\omega 3$ & $4.4(1.5)$ & 4.2 & $4.2(1.4)$ & 4.0 & 0.186 \\
\hline$\omega 6: \omega 3$ & $0.2(0.1)$ & 0.2 & $0.2(0.1)$ & 0.2 & 0.318 \\
\hline
\end{tabular}

MUFA, mono unsaturated fatty acid; PUFA, poly unsaturated fatty acid; AA, arachidonic acid (20:4n-6); EPA, eicosapentaenoic acid (20:5n-3).

metabolite levels caused by nutritional deficiencies or inflammation $(19,23,40)$. It thus can be a valuable tool for assessing the metabolic background of chronic inflammatory disorders prior to the onset of symptoms $(41,42)$.

The approach used in this study focused on the quantification of 24 FAs and evaluation of their relative levels. Thus, it allowed the estimation of intake via different sources and provided a reliable assessment of nutritional status and dietary habits. Unlike dietary frequency questionnaires, FA profiling enables the estimation of dietary intake and endogenous FA synthesis (6). The clinical importance of measuring FAs is associated with their essential roles in inflammation (43).

An analysis of PUFA levels in 1,123 healthy adults by Ferrucci et al revealed a strong negative correlation between omega-6/omega-3 ratiosand IL-10, an anti-inflammatory cytokine; omega-3 levels positively correlated with the levels of anti-inflammatory cytokines (44). The results of studies of the associations between omega- 3 intake and inflammation suggested that these FAs are associated with the prevention of cardiovascular disease $(45,46)$, Parkinson's symptoms and metabolic state (47). The omega-6/omega-3 ratio has long been used as a representative measure of dietary fat intake with multiple implications for chronic disease severity (48). Most interventional studies on the supplementation of omega-3 FAs in patients with chronic disorders have examined the beneficial anti-inflammatory properties of these FAs, particularly for rheumatoid arthritis (49). However, dietary recommendations on omega-3 FA intake are not consistent and vary in FA source and dose (33). 


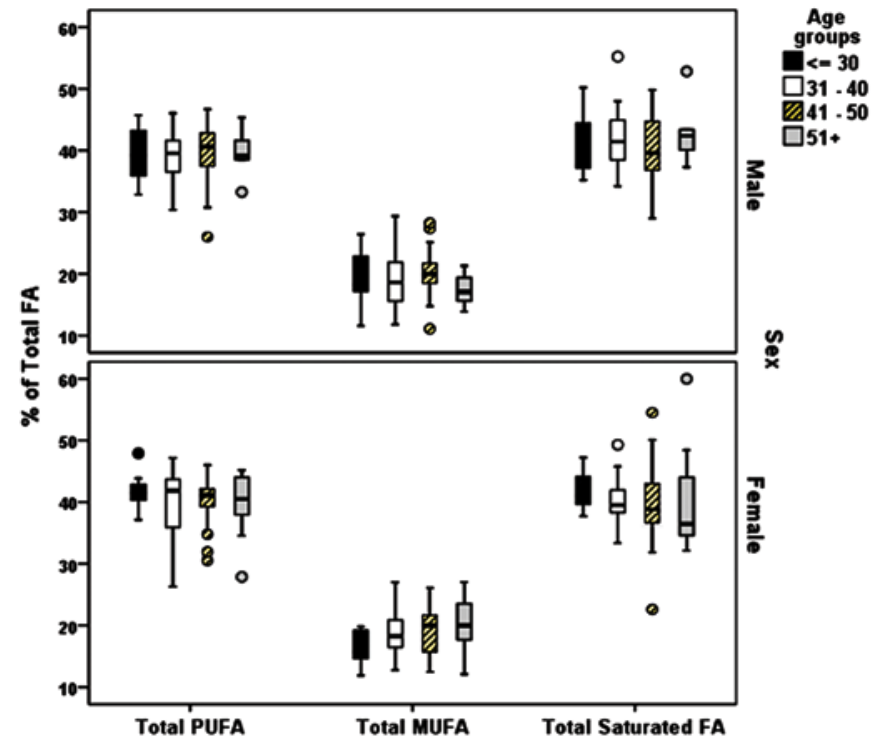

Figure 2. Composition of fatty acids. Percentage total fatty acids per age group in males and females. MUFA, monounsaturated fatty acid; PUFA, polyunsaturated fatty acid; AA, arachidonic acid (20:4n-6); EPA, eicosapentaenoic acid (20:5n-3)

The roles of omega- 6 FAs are not yet fully understood $(50,51)$. LA, the major omega- 6 FA, has long been regarded as harmful and atherogenic. However, LA may be highly beneficial as part of a low-SFA diet (50). LA is the precursor of many bioactive molecules, including pro-inflammatory eicosanoids and inflammation suppression molecules. By contrast, the LA-produced dihomo-gamma-linolenic acid (DGLA) mostly acts as a substrate for anti-inflammatory molecules. However, at high levels, it is desaturated to AA to participate in the formation of inflammatory eicosanoids (52). Increased levels of DGLA are associated with high insulin levels and insulin resistance in patients with type 2 diabetes $(53,54)$. Our study revealed DGLA RVs of $73.5-124 \mu \mathrm{mol} / 1$ in a healthy population. Tissue sensitivity to insulin is associated with the AA/EPA ratio. Thus, AA production is regulated in an insulin-dependent manner. EPA is an AA antagonist and a substrate for anti-inflammatory eicosanoid production (i.e., series-3 prostaglandins, thromboxanes, and 5-series leukotrienes). Therefore, the AA/EPA ratio is a sensitive marker of the balance between omega- 6 and omega-3 and the trend in pro-inflammatory eicosanoid production (55). High AA/EPA levels are associated with arterial stiffness in patients with obesity and dyslipidemia (56) and acute coronary syndrome; this ratio may be useful as a diagnostic marker for cardiovascular disease $(57,58)$. Our results indicated that the range in values for the AA/EPA ratio was 6.8-14.1 for a healthy population; these values were likely associated with modern dietary habits. Omega-9 MUFAs are produced endogenously from SFAs and are subsequently catalyzed by the delta- 9 desaturase. When insulin levels or insulin resistance are elevated, the inhibition of desaturase results in elevated levels of palmitic and stearic acid. Hence, FA composition and desaturase activity are associated with insulin resistance (54). Compared with intake of a diet high in carbohydrates, the consumption of a MUFA-rich diet is associated with beneficial effects on values for metabolic
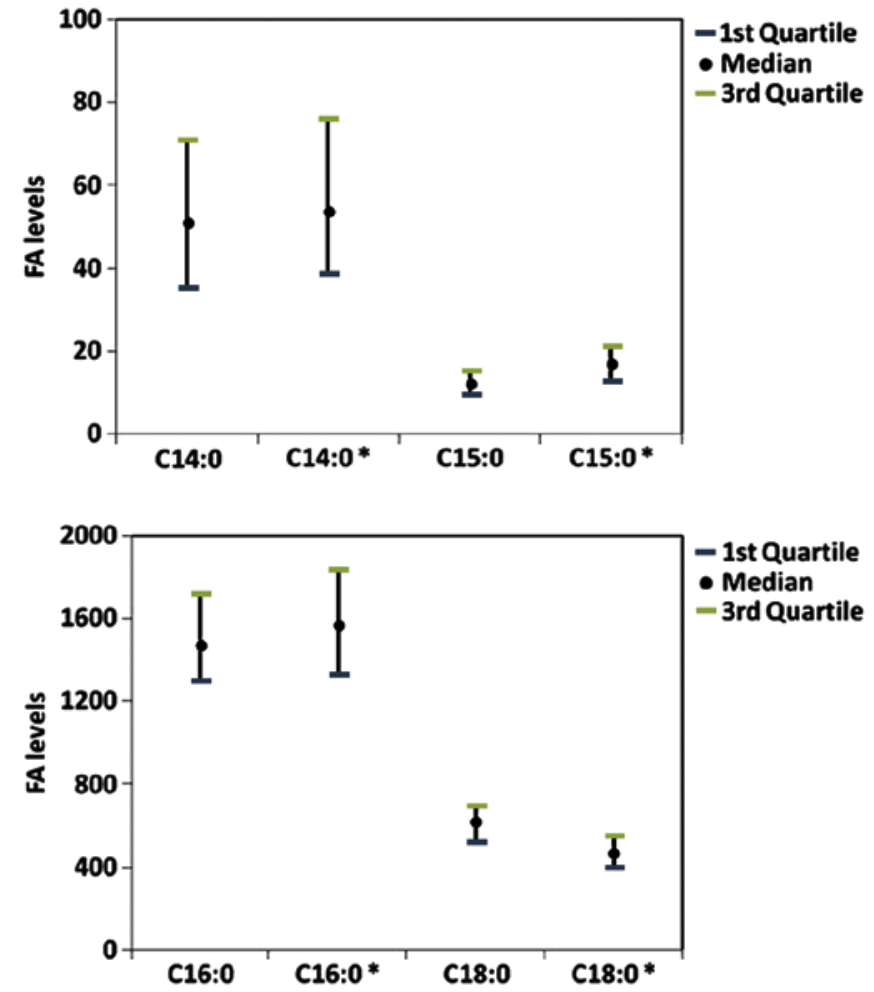

Figure 3. Total saturated fatty acids. Levels of total saturated fatty acids 14:0, 15:0 (upper panel) and 16:0, 18:0 (bottom panel) in our population and in healthy Canadian adults [marked with an asterisk $(*)(27)]$.

parameters including blood pressure, glycemic levels, and serum lipids (59).

One strength of this study was the presentation of RV results as FA concentrations. These results can be compared and applied in future clinical studies. To eliminate differences in total FA levels among individuals that could affect the FA profiling results, differences among age groups and sex were evaluated using relative values within the FA pool. In most similar studies, RVs are reported as percent composition; the value of each FA depends on the relative levels of the other measured FAs. However, this type of approach is more appropriate for nutrition studies or comparisons between groups in a well-defined population in which FA values are affected by total FAs. The use of concentration values is a more reliable approach for the study of the direct associationbetween a specific FA and a biological mechanism or outcome, and thus can be used as biomarkers (60).

The assessment of FA composition can be performed in adipose tissue, erythrocytes, platelets, whole blood and plasma (29). Circulating FAs mainly reflect the dietary intake several weeks before sampling. FA values obtained from erythrocytes and adipose tissue reveal habits of months and years, respectively. Plasma contains all lipid fractions, including triglycerides, cholesteryl esters and free FAs. To achieve an overall evaluation of FA levels, the total FA composition should be assessed (61). Consistent with this requirement, we used a GC-MS method in this study; the lipid fractions were hydrolyzed, and the FAs were esterified to methylesters, which allowed estimation of the total FAs contained in plasma (37).

This study had some limitations. As the population consisted of Greek individuals, the results should be interpreted with 
caution when applied to individuals from other geographical areas. In a systematic review, Stark et al found wide fluctuations in physiological blood FA levels between individuals around the globe, particularly for EPA and DHA; different dietary habits accounted for most of the differences (26). FA levels are primarily affected by dietary habits. This association can be illustrated by the elevated levels of stearic acid $(\mathrm{P}=0.005)$ and omega-6/omega-3 ratios $(\mathrm{P}=0.027)$ found in the participants $<30$ years of age (Table I). Adults in this age group tend to consume carbohydrate-rich diets with a low or no intake of vegetables, fruits, nuts, fish and other sources of beneficial fats (62). Compared with the male participants, female participants in the age group $>30$ years had lower total SFA and increased MUFA levels (Fig. 2). However, there were no between-group differences in PUFA levels for age or sex. The differences in the AA/EPA ratio $(\mathrm{P}<0.0001)$ and in DGLA $(\mathrm{P}=0.046)$ also indicated the effects of diet on the metabolic profile results (63). Many of the plasma FA concentrations found in a study of healthy adults in Canada were similar to the RV results observed in our population (27). The results for myristic acid, pentadecanoic acid, palmitic acid, and stearic acid were almost identical between the two datasets (Fig. 3). Therefore, despite demographic differences, the levels of some FAs may be similar among populations and can thus be used as biomarkers.

In the healthy Greek population examined in the ATTICA study, the results for the relative levels of the major FAs were also very similar to the results of our study (30). The mean relative values for total omega- $6(33.75 \%)$ and total omega-3 (2.66\%) were identical to the values for our population set (35.74 and $4.32 \%)$, respectively. The results for AA $(5.17 \%)$ and DHA $(1.56 \%)$ were also not markedly different from the results obtained in our study (6.82 and 2.2\%, respectively) (Table S2). The ATTICA sample size was larger, and the FAs were evaluated using a different laboratory method. However, the results of this comparison with the results of the ATTICA study emphasizes the strength of the metabolomics approach and the consistency among population sets. Even though we cannot extrapolate our findings to other populations, results from previous and present studies highlight the value of metabolomics and FAs for biomarker identification.

In conclusion, the identification of FA imbalances through metabolomics analysis will allow the early detection of metabolism dysfunction. Its application may be useful for both the diagnosis and prevention of chronic inflammatory diseases. The data of this study contribute to the establishment of sensitive RVs for FAs. These RVs can be combined with the RVs for organic acids (38) and can be examined in clinical studies to assess their validity and reliability as biomarkers for various chronic diseases in different populations. For successful application to clinical practice, further research based on the current approach is required in order to develop a standardized methodology and RVs for panels of FAs.

\section{Acknowledgements}

The authors would like to thank all the administrative, technical and medical staff of Toxplus, the Metabolomic Clinic, and the Laboratory of Toxicology for their dedicated involvement in this study.

\section{Funding}

This study was funded by Metabolomic Clinic S.A. and Toxplus S.A. and supported by the Special Research Account of University of Crete (ELKE nos. 4602, 4920 and 3963).

\section{Availability of data and materials}

The datasets presented in this study are available from the corresponding author upon reasonable request.

\section{Authors' contributions}

DT, AT and DAS conceived and designed the study; DT and GT collected the samples and performed clinical measurements; EP performed the serum FA targeted metabolomic analysis; $\mathrm{PF}$ and $\mathrm{ES}$ performed the data processing and quality control assessment; AKA, DN and FG performed the statistical analysis. All authors reviewed and approved the manuscript before submission.

\section{Ethics approval and consent to participate}

All procedures performed in studies involving human participants were under the ethical standards with the 1964 Helsinki declaration and its later amendments, or comparable ethical standards. An informed consent was obtained from all participants for this study according to the EU General Data Protection Regulation (GDPR).

\section{Patient consent for publication}

Not applicable.

\section{Competing interests}

DAS is the Editor-in-Chief for the journal, but had no personal involvement in the reviewing process, or any influence in terms of adjudicating on the final decision, for this article.

\section{References}

1. Daley CA, Abbott A, Doyle PS, Nader GA and Larson S: A review of fatty acid profiles and antioxidant content in grass-fed and grain-fed beef. Nutr J 9: 10, 2010.

2. Kris-Etherton PM, Harris WS and Appel LJ; Nutrition Committee: Fish consumption, fish oil, omega-3 fatty acids, and cardiovascular disease. Arterioscler Thromb Vasc Biol 23: e20-e30, 2003.

3. Blasbalg TL, Hibbeln JR, Ramsden CE, Majchrzak SF and Rawlings RR: Changes in consumption of omega- 3 and omega- 6 fatty acids in the United States during the 20th century. Am J Clin Nutr 93: 950-962, 2011.

4. Bosma-den Boer MM, van Wetten ML and Pruimboom L: Chronic inflammatory diseases are stimulated by current lifestyle: How diet, stress levels and medication prevent our body from recovering. Nutr Metab (Lond) 9: 32, 2012.

5. Engin AB, Tsatsakis AM, Tsoukalas D and Engin A: Do flavanols-rich natural products relieve obesity-related insulin resistance? Food Chem Toxicol 112: 157-167, 2018.

6. Simopoulos AP and DiNicolantonio JJ: The importance of a balanced $\omega-6$ to $\omega-3$ ratio in the prevention and management of obesity. Open Heart 3: e000385, 2016.

7. Patterson E, Wall R, Fitzgerald GF, Ross RP and Stanton C: Health implications of high dietary omega- 6 polyunsaturated Fatty acids. J Nutr Metab 2012: 539426, 2012. 
8. Liu Y, Song A, Yang X, Zhen Y, Chen W, Yang L, Wang C and $\mathrm{Ma}$ H: Farnesoid X receptor agonist decreases lipid accumulation by promoting hepatic fatty acid oxidation in $\mathrm{db} / \mathrm{db}$ mice. Int $\mathrm{J}$ Mol Med 42: 1723-1731, 2018

9. Feng L, Dou C, Wang J, Jiang C, Ma X and Liu J: Upregulated 14 $33 \beta$ aggravates restenosis by promoting cell migration following vascular injury in diabetic rats with elevated levels of free fatty acids. Int J Mol Med 42: 1074-1085, 2018.

10. Nathan C and Ding A: Nonresolving inflammation. Cell 140: 871-882, 2010.

11. Tabas I: Macrophage death and defective inflammation resolution in atherosclerosis. Nat Rev Immunol 10: 36-46, 2010.

12. Chimenti MS, Triggianese P, Conigliaro P, Candi E, Melino G and Perricone R: The interplay between inflammation and metabolism in rheumatoid arthritis. Cell Death Dis 6: e1887,2015.

13. Roxburgh CS and McMillan DC: Cancer and systemic inflammation: Treat the tumour and treat the host. Br J Cancer 110: 1409-1412, 2014

14. Donath MY and Shoelson SE: Type 2 diabetes as an inflammatory disease. Nat Rev Immunol 11: 98-107, 2011.

15. Zafiropoulos A, Linardakis M, Jansen EHJM, Tsatsakis AM, Kafatos A and Tzanakakis GN: Paraoxonase $1 \mathrm{R} / \mathrm{Q}$ alleles are associated with differential accumulation of saturated versus 20:5n3 fatty acid in human adipose tissue. J Lipid Res 51: 1991-2000, 2010

16. Nicholson JK: Global systems biology, personalized medicine and molecular epidemiology. Mol Syst Biol 2: 52, 2006.

17. Karczewski KJ and Snyder MP: Integrative omics for health and disease. Nat Rev Genet 19: 299-310, 2018

18. Wenk MR: The emerging field of lipidomics. Nat Rev Drug Discov 4: 594-610, 2005.

19. Zhao L, Ni Y, Ma X, Zhao A, Bao Y, Liu J, Chen T, Xie G, Panee J, Su M, et al: A panel of free fatty acid ratios to predict the development of metabolic abnormalities in healthy obese individuals. Sci Rep 6: 28418, 2016.

20. Matthan NR, Ooi EM, Van Horn L, Neuhouser ML, Woodman R and Lichtenstein AH: Plasma phospholipid fatty acid biomarkers of dietary fat quality and endogenous metabolism predict coronary heart disease risk: A nested case-control study within the Women's Health Initiative observational study. J Am Heart Assoc 3: 14-16, 2014.

21. Harris WS, Luo J, Pottala JV, Margolis KL, Espeland MA and Robinson JG: Red blood cell fatty acids and incident diabetes mellitus in the women's health initiative memory study. PLoS One 11: e0147894, 2016.

22. Shaw J: Fathoming metabolism. The study of metabolites does an end run around genomics to provide telling clues to your future health. Harv Mag 3: 27-31, 2011.

23. Wang TJ, Larson MG, Vasan RS, Cheng S, Rhee EP, McCabe E, Lewis GD, Fox CS, Jacques PF, Fernandez C, et al: Metabolite profiles and the risk of developing diabetes. Nat Med 17: 448-453, 2011.

24. Cheng S, Larson MG, Mccabe EL, Murabito JM, Rhee EP, Ho JE, Jacques PF, Ghorbani A, Magnusson M, Souza AL, et al: Distinct metabolomic signatures are associated with longevity in humans. Nat Commun 6: 6791, 2015.

25. Clish CB: Metabolomics: An emerging but powerful tool for precision medicine. Cold Spring Harb Mol Case Stud 1: a000588, 2015.

26. Stark KD, Van Elswyk ME, Higgins MR, Weatherford CA and Salem N Jr: Global survey of the omega-3 fatty acids, docosahexaenoic acid and eicosapentaenoic acid in the blood stream of healthy adults. Prog Lipid Res 63: 132-152, 2016.

27. Abdelmagid SA, Clarke SE, Nielsen DE, Badawi A,El-Sohemy A, Mutch DM and Ma DW: Comprehensive profiling of plasma fatty acid concentrations in young healthy Canadian adults. PLoS One 10: e0116195, 2015.

28. Perreault M, Roke K, Badawi A, Nielsen DE, Abdelmagid SA, El-Sohemy A, Ma DW and Mutch DM: Plasma levels of 14:0, $16: 0,16: 1 n-7$, and 20:3n-6 are positively associated, but 18:0 and 18:2n-6 are inversely associated with markers of inflammation in young healthy adults. Lipids 49: 255-263, 2014

29. Risé P, Eligini S, Ghezzi S, Colli S and Galli C: Fatty acid composition of plasma, blood cells and whole blood: Relevance for the assessment of the fatty acid status in humans. Prostaglandins Leukot Essent Fatty Acids 76: 363-369, 2007.

30. Kalogeropoulos N, Panagiotakos DB, Pitsavos C, Chrysohoou C, Rousinou G, Toutouza M and Stefanadis C: Unsaturated fatty acids are inversely associated and n-6/n-3 ratios are positively related to inflammation and coagulation markers in plasma of apparently healthy adults. Clin Chim Acta 411: 584-591, 2010.
31. Baum SJ: A survey of internists and cardiologists: Are discoveries in fatty acids truly being translated into clinical practice? Prostaglandins Leukot Essent Fatty Acids 88: 3-4, 2013.

32. Hudita A, Galateanu B, Dinescu S, Costache M, Dinischiotu A, Negrei C, Stan M, Tsatsakis A, Nikitovic D, Lupuliasa D, et al: In vitro effects of cetylated fatty acids mixture from celadrin on chondrogenesis and inflammation with impact on osteoarthritis. Cartilage: May 1, 2018 (Epub ahead of print). doi: $10.1177 / 1947603518775798$.

33. Weylandt KH, Serini S, Chen YQ, Su HM, Lim K, Cittadini A and Calviello G: Omega-3 polyunsaturated fatty acids: The way forward in times of mixed evidence. Biomed Res Int 2015: 143109,2015

34. Simopoulos AP: An increase in the Omega-6/Omega-3 fatty acid ratio increases the risk for obesity. Nutrients 8: 128, 2016

35. Yang YJ, Choi MH, Paik MJ, Yoon HR and Chung BC: Gas chromatographic-mass spectrometric determination of plasma saturated fatty acids using pentafluorophenyldimethylsilyl derivatization. J Chromatogr B Biomed Sci Appl 742: 37-46, 2000.

36. Ruiter AF, Ackermans MT and Endert E: Simultaneous gas chromatographic determination of concentration and isotopic enrichment of fatty acids in human plasma using flame ionization and mass spectrometric detection. J Chromatogr B Biomed Sci Appl 759: 169-174, 2001.

37. Ecker J, Scherer M, Schmitz G and Liebisch G: A rapid GC-MS method for quantification of positional and geometric isomers of fatty acid methyl esters. J Chromatogr B Analyt Technol Biomed Life Sci 897: 98-104, 2012.

38. Tsoukalas D, Alegakis A, Fragkiadaki P, Papakonstantinou E, Nikitovic D, Karataraki A, Nosyrev AE, Papadakis EG, Spandidos DA, Drakoulis N, et al: Application of metabolomics: Focus on the quantification of organic acids in healthy adults. Int J Mol Med 40: 112-120, 2017.

39. Stellaard F, ten Brink HJ, Kok RM, van den Heuvel L and Jakobs C: Stable isotope dilution analysis of very long chain fatty acids in plasma, urine and amniotic fluid by electron capture negative ion mass fragmentography. Clin Chim Acta 192: 133-144, 1990.

40. Cheng S, Rhee EP, Larson MG, Lewis GD, McCabe EL, Shen D, Palma MJ, Roberts LD, Dejam A, Souza AL, et al: Metabolite profiling identifies pathways associated with metabolic risk in humans. Circulation 125: 2222-2231, 2012.

41. Calder PC, Albers R, Antoine JM, Blum S, Bourdet-Sicard R, Ferns GA, Folkerts G, Friedmann PS, Frost GS, Guarner F, et al: Inflammatory disease processes and interactions with nutrition. Br J Nutr 101 (Suppl 1): S1-S45, 2009.

42. Holmes E, Wilson ID and Nicholson JK: Metabolic phenotyping in health and disease. Cell 134: 714-717, 2008.

43. Galli $\mathrm{C}$ and Calder PC: Effects of fat and fatty acid intake on inflammatory and immune responses: A critical review. Ann Nutr Metab 55: 123-139, 2009.

44. Ferrucci L, Cherubini A, Bandinelli S, Bartali B, Corsi A Lauretani F, Martin A, Andres-Lacueva C, Senin U and Guralnik JM: Relationship of plasma polyunsaturated fatty acids to circulating inflammatory markers. J Clin Endocrinol Metab 91: 439-446, 2006

45. Bersch-Ferreira AC, Sampaio GR, Gehringer MO, RossFernandes MB, Kovacs C, Alves R, Pereira JL, Magnoni CD, Weber B and Rogero MM: Association between polyunsaturated fatty acids and inflammatory markers in patients in secondary prevention of cardiovascular disease. Nutrition 37: 30-36, 2017.

46. Harris WS, Del Gobbo L and Tintle NL: The Omega-3 Index and relative risk for coronary heart disease mortality: Estimation from 10 cohort studies. Atherosclerosis 262: 51-54, 2017.

47. Taghizadeh M, Tamtaji OR, Dadgostar E, Daneshvar Kakhaki R, Bahmani F, Abolhassani J, Aarabi MH, Kouchaki E, Memarzadeh MR and Asemi Z: The effects of omega-3 fatty acids and vitamin E co-supplementation on clinical and metabolic status in patients with Parkinson's disease: A randomized, double-blind, placebo-controlled trial. Neurochem Int 108: 183-189, 2017.

48. Simopoulos AP: The importance of the omega-6/omega-3 fatty acid ratio in cardiovascular disease and other chronic diseases. Exp Biol Med (Maywood) 233: 674-688, 2008.

49. Miles EA and Calder PC: Influence of marine n-3 polyunsaturated fatty acids on immune function and a systematic review of their effects on clinical outcomes in rheumatoid arthritis. Br J Nutr 107 (Suppl 2): S171-S184, 2012.

50. Farvid MS, Ding M, Pan A, Sun Q, Chiuve SE, Steffen LM, Willett WC and Hu FB: Dietary linoleic acid and risk of coronary heart disease: A systematic review and meta-analysis of prospective cohort studies. Circulation 130: 1568-1578, 2014. 
51. Harris WS, Mozaffarian D, Rimm E, Kris-Etherton P, Rudel LL, Appel LJ, Engler MM, Engler MB and Sacks F: Omega-6 fatty acids and risk for cardiovascular disease: A science advisory from the American Heart Association nutrition subcommittee of the council on nutrition, physical activity, and metabolism; council on cardiovascular nursing; and council on epidem. Circulation 119: 902-907, 2009.

52. Kohli $\mathrm{P}$ and Levy BD: Resolvins and protectins: Mediating solutions to inflammation. Br J Pharmacol 158: 960-971, 2009.

53. Yamashita K, Higa M, Kunishita R, Kanazawa K, Tasaki M, Doi A, Yoshifuji A, Ichijo T, Ouchi $\mathrm{H}$ and Hirose T: Ayumi Yoshifuji, Takamasa Ichijo, Hiromi Ouchi and Takahisa Hirose: Dihomo-gamma-linolenic acid levels and obesity in patients with type 2 diabetes. Diabetol Int 6: 206-211, 2015.

54. Kurotani K, Sato M, Ejima Y, Nanri A, Yi S, Pham NM, Akter S, Poudel-Tandukar K, Kimura Y, Imaizumi K, et al: High levels of stearic acid, palmitoleic acid, and dihomo- $\gamma$-linolenic acid and low levels of linoleic acid in serum cholesterol ester are associated with high insulin resistance. Nutr Res 32: 669-675.e3, 2012.

55. Greene ER, Huang S, Serhan CN and Panigrahy D: Regulation of inflammation in cancer by eicosanoids. Prostaglandins Other Lipid Mediat 96: 27-36, 2011.

56. Ito R, Satoh-Asahara N, Yamakage H, Sasaki Y, Odori S, Kono S, Wada H, Suganami T, Ogawa Y, Hasegawa K, et al: An increase in the EPA/AA ratio is associated with improved arterial stiffness in obese patients with dyslipidemia. J Atheroscler Thromb 21: 248-260, 2014

57. Iwamatsu K, Abe S, Nishida H, Kageyama M, Nasuno $T$, Sakuma M, Toyoda S and Inoue T: Which has the stronger impact on coronary artery disease, eicosapentaenoic acid or docosahexaenoic acid? Hypertens Res 39: 272-275, 2016.
58. Wakabayashi Y, Funayama H, Ugata Y, Taniguchi Y, Hoshino H, Ako J and Momomura S: Low eicosapentaenoic acid to arachidonic acid ratio is associated with thin-cap fibroatheroma determined by optical coherence tomography. J Cardiol 66: 482-488, 2015.

59. Qian F, Korat AA, Malik V and Hu FB: Metabolic effects of monounsaturated fatty acid-enriched diets compared with carbohydrate or polyunsaturated fatty acid-enriched diets in patients with type 2 diabetes: A systematic review and meta-analysis of randomized controlled trials. Diabetes Care 39: 1448-1457, 2016.

60. Schwertner HA and Mosser EL: Comparison of lipid fatty acids on a concentration basis vs weight percentage basis in patients with and without coronary artery disease or diabetes. Clin Chem 39: 659-663, 1993.

61. Lagerstedt SA, Hinrichs DR, Batt SM, Magera MJ, Rinaldo P and McConnell JP: Quantitative determination of plasma c8-c26 total fatty acids for the biochemical diagnosis of nutritional and metabolic disorders. Mol Genet Metab 73: 38-45, 2001.

62. Poobalan A and Aucott L: Obesity among young adults in developing countries: A systematic overview. Curr Obes Rep 5: 2-13, 2016 .

63. Li K, Brennan L, McNulty BA, Bloomfield JF, Duff DJ, Devlin NF, Gibney MJ, Flynn A, Walton J and Nugent AP: Plasma fatty acid patterns reflect dietary habits and metabolic health: A cross-sectional study. Mol Nutr Food Res 60: 2043-2052, 2016. International (CC BY-NC-ND 4.0) License. 